\title{
Child and Adolescent
}

Mental Health

a journal for all professionals working

with children and young people

\section{Using Patient Reported Outcome Measures to Improve Service Effectiveness for Supervisors (UPROMISES): A mixed-methods evaluation of supervisors' attitudes and self-efficacy after training to use outcome measures in child mental health}

\begin{tabular}{|c|c|}
\hline Journal: & Child and Adolescent Mental Health \\
\hline Manuscript ID & CAMH-OA-2016-0084.R1 \\
\hline Wiley - Manuscript type: & Original Article \\
\hline Date Submitted by the Author: & $\mathrm{n} / \mathrm{a}$ \\
\hline Complete List of Authors: & $\begin{array}{l}\text { Fullerton, Mary; East Haringey IAPT Whittington Health NHS Trust } \\
\text { Edbrooke-Childs, Julian; UCL and the Anna Freud Centre, Evidence-Based } \\
\text { Practice Unit } \\
\text { Law, Duncan ; The Anna Freud Centre } \\
\text { Martin, Kate; Common Room Consulting Ltd } \\
\text { Whelan, Isabelle; UCL and the Anna Freud Centre, Evidence-Based Practice } \\
\text { Unit } \\
\text { Wolpert, Miranda; Evidence Based Practice Unit }\end{array}$ \\
\hline Key Words: & Outcome, Evaluation, Mental health, Implementation, Service development \\
\hline Abstract: & $\begin{array}{l}\text { Background: Patient-reported outcome measures (PROMs) are } \\
\text { recommended by healthcare systems internationally, but there are a } \\
\text { number of barriers to implementation. The aim of the present research was } \\
\text { to examine the impact of training supervisors in using PROMs on clinical } \\
\text { practice, given the importance of leadership when changing behaviour. } \\
\text { Method: Data included pre-post questionnaires from } 42 \text { supervisors, } \\
\text { interviews after training with six supervisees, and non-participant } \\
\text { observations of nine video-recorded supervision sessions. } \\
\text { Results: After training, supervisors had more positive attitudes to } \\
\text { administering PROMs and using feedback from PROMs, and had higher } \\
\text { levels of self-efficacy about using PROMs in supervision. } \\
\text { Conclusions: Findings are in line with the growing body of evidence that } \\
\text { training child mental health staff to use PROMs may be associated with } \\
\text { changes in attitudes, self-efficacy and use of PROMs. }\end{array}$ \\
\hline
\end{tabular}


RUNNING HEAD: TRAINING SUPERVISORS TO USE PROMS

\section{Using Patient Reported Outcome Measures to Improve Service Effectiveness for} Supervisors (UPROMISES): A mixed-methods evaluation of supervisors' attitudes and self-efficacy after training to use outcome measures in child mental health

Mary Fullerton ${ }^{1}$, Dr Julian Edbrooke-Childs ${ }^{2}$, Dr Duncan Law ${ }^{3}$, Kate Martin ${ }^{4}$, Isabelle Whelan $^{2} \&$ Dr Miranda Wolpert ${ }^{2}$

\section{Affiliations}

${ }^{1}$ East Haringey IAPT, Whittington Health NHS Trust, 1a Lansdowne Road, Tottenham, N17 OLL

${ }^{2}$ Evidence Based Practice Unit, UCL and the Anna Freud Centre, 12 Maresfield Gardens, London, NW3 5SU

${ }^{3}$ The Anna Freud Centre, 12 Maresfield Gardens, London, NW3 5S

${ }^{4}$ Common Room Consulting Ltd.

Corresponding author: Dr Miranda Wolpert, Evidence Based Practice Unit, UCL and the Anna Freud Centre, 12 Maresfield Gardens, London, NW3 5SU; ebpu@,annafreud.org 
TRAINING SUPERVISORS TO USE PROMS 2

\begin{abstract}
Background: Patient-reported outcome measures (PROMs) are recommended by healthcare systems internationally, but there are a number of barriers to implementation. The aim of the present research was to examine the impact of training supervisors in using PROMs on clinical practice, given the importance of leadership when changing behaviour.

Method: Data included pre-post questionnaires from 42 supervisors, interviews after training with six supervisees, and non-participant observations of nine video-recorded supervision sessions.
\end{abstract}

Results: After training, supervisors had more positive attitudes to administering PROMs and using feedback from PROMs, and had higher levels of self-efficacy about using PROMs in supervision.

Conclusions: Findings are in line with the growing body of evidence that training child mental health staff to use PROMs may be associated with changes in attitudes, self-efficacy and use of PROMs.

\title{
Key practitioner message
}

- Specific training in use of PROMS was associated with an increase in supervisors' positive attitude and self-efficacy related to administering PROMs and using feedback from PROMS in supervision.

- Observations indicated that supervisors had high levels of competence related to discussing PROMs in supervision, but were not entirely consistent in discussing in supervision with clinicians how PROMs were administered.

- The results are in line with a growing body of evidence that training child mental health staff to use PROMs may be associated with changes in attitudes, self-efficacy and use of PROMs. 
TRAINING SUPERVISORS TO USE PROMS 3

Keywords: mental health; evaluation; outcome;

Word count: 3,496 of 5,500 max 


\section{Using Patient Reported Outcome Measures to Improve Service Effectiveness for} Supervisors (UPROMISES): A mixed-methods evaluation of supervisors' attitudes and self-efficacy after training to use outcome measures in child mental health Patient reported outcome measures (PROMs) are recommended by healthcare systems internationally (Department of Health, 2011; SAMHSA's National Registry of EvidenceBased Programs and Practices, 2015) to aid communication and collaboration between patients and clinicians and to help understand what treatments are — and are not—working (Carlier et al., 2012; Lambert et al., 2003). Evidence suggests that feedback from outcome measures is associated with higher levels of treatment effectiveness, especially when provided to both patients and clinicians and when patients are not responding to therapy as expected (Bickman, Kelley, Breda, de Andrade, \& Riemer, 2011; Gondek, Edbrooke-Childs, Fink, Deighton, \& Wolpert, 2016).

Still, there are a number of barriers to using PROMs (Boswell, Kraus, Miller, \& Lambert, 2013; Douglas, Button, \& Casey, 2014; Mellor-Clark, Cross, Macdonald, \& Skjulsvik, 2016). For instance, outcome measures have been routinely used in mental health services in Australia since 2003, and a 10 year review concluded that it had taken a decade to establish the necessary infrastructure and resources to support routine data collection (Burgess, Coombs, Clarke, Dickson, \& Pirkis, 2012).

Clinicians report being reluctant to use outcome measures even if it improved patient care (Walter, Cleary, \& Rey, 1998). A mixed-methods study demonstrated that barriers may centre on the feasibility and acceptability of the system, rather than the outcome measures themselves. Indeed in this paper, feedback tools were generally found to be positively thought of, but not routinely discussed in supervision or used as a tool in treatment-making decisions (Lucock et al., 2015). Survey and case note audit studies have found the use of measures at one time point to range from $65-87 \%$ but at more than one time point from only 
16-40\% (Batty et al., 2013; Johnston \& Gowers, 2005; Mellor-Clark, Barkham, Connell, \& Evans, 1999). Another study found that the use of measures at more than one time point doubled from $30 \%$ to $60 \%$ with support from a learning collaboration (Hall et al., 2013). Regularly reviewing feedback from measures may be more likely when children present with more common problems such as anxiety and mood problems but less likely when they present with more complex cases, such as those involving children under state care or those in need of social service input (Edbrooke-Childs, Gondek, Deighton, Fonagy, \& Wolpert, 2016; Moran, Kelesidi, Guglani, Davidson, \& Ford, 2012; Miranda Wolpert, Curtis-Tyler, \& Edbrooke-Childs, 2016).

Clinicians are more likely to use outcome measures when they believe that measures are clinically useful (Jensen-Doss \& Hawley, 2010). Similarly, clinicians are more likely to use feedback from outcome measures when they hold a positive attitude to feedback (de Jong, van Sluis, Nugter, Heiser, \& Spinhoven, 2012). There is a growing body of evidence on the association between training clinicians to use PROMs and PROM attitude, self-efficacy, and use in clinical practice, as outlined below in Figure 1. In particular, training clinicians in the use of measures and feedback has been shown to be associated with more positive attitudes and higher levels of self-efficacy related to using measures (Edbrooke-Childs, Wolpert, \& Deighton, 2016) and ideas about their usefulness in practice (Trauer, Pedwell, \& Lisa, 2009). Moreover, positive PROM attitudes and higher levels of PROM self-efficacy have been shown to be associated with higher levels of PROM use (Edbrooke-Childs et al., submitted). However, changing attitudes and self-efficacy alone may be inadequate to bring about changes to everyday clinical practice.

[INSERT FIGURE 1 HERE] 
In general, implementation science research has identified important facilitators of change, including strong leadership and management support and an organisational culture where change is seen as non-threatening (Hoag, Ritschard, \& Cooper, 2002). In healthcare, training is a common intervention for implementing new practices, as it provides the opportunity to identify local strategies for overcoming practical barriers to implementation, including staff turnover and limited time and resources (Elliott, Ashton, Gerrard, \& Cox, 2003; The Health Foundation, 2012). Other benefits of training include experiential learning, which helps trainees move through the stages of behaviour change from experiencing, observing, conceptualising, to retrying; e.g., with role plays and discussion (Batalden \& Davidoff, 2007; Kolb, 1984; Oordt, Jobes, Fonseca, \& Schmidt, 2009). A recent systematic review of training evaluations found the strongest supportive evidence for multi-component training (Herschell, Kolko, Baumann, \& Davis, 2010). If changes to practice are to be successfully implemented and sustained, they need to be perceived as important and prioritised by the service and staff (Aoun, Pennebaker, \& Janca, 2002). To understand this further, we need to look at what happens after implementation and the actions of those embedding innovations successfully or not (Fixsen, Naoom, Blase, Friedman, \& Wallace, 2005).

The process and theory of supervision in psychological therapy and across mental health settings has been much studied and research has attempted to focus on the impact and effectiveness of supervision. Evidence tends to demonstrate positive effects (see Roth \& Pilling, 2008) but while supervision appears to affect therapist behaviour positively, it remains difficult to summarise its impact on patient outcome from research to date (Watkins, 2011). Some research, while without control group comparison, demonstrates a reduction in psychotic symptoms of patients through additional workplace supervision for nurses (Bradshaw, Butterworth, \& Mairs, 2007), while other studies demonstrate no significant 
differences in patient outcome or satisfaction through increased supervision (White \& Winstanley, 2010), and that variance in therapy was explained by less than $1 \%$ by supervisor in a large 5-year sample (Rousmaniere, Swift, Babins-Wagner, Whipple, \& Berzins, 2016).

More evidence exists on the positive effect of well-structured supervision on the supervisees' behaviours and attitudes-such as learning new skills and fidelity to model-that are likely to impact on clinical outcomes in turn (see Watkins Jr \& Milne, 2014). On its own, training in new practices increases clinicians' knowledge, but changes in behaviour are greater when training is supported in supervision (Bearman, Schneiderman, \& Zoloth, 2016). Furthermore, supervision has been shown to impact on wider culture change, with supervisors playing a vital role in quality improvement across organisations (Kihlgren \& Hansebo, 2014) often influencing several members of staff. It is clear that there is much variation in supervision practice (Schoenwald, Sheidow, \& Chapman, 2009), with systematisation required in order to encourage effective implementation of evidence-based practice (O'Donovan, Halford, \& Walters, 2011). Milne (2016) argues that to be effective, supervision needs to be well structured and informed by feedback - evidence-based supervision leads to evidence-based practice. The competencies of good supervisors are embedded in the UK's Children and Young People's Improving Access to Psychological Therapies (CYP IAPT) programme where the systematic training of supervisors is seen as a vital part of a developing a quality service (Turpin \& Wheeler, 2011). It is this aspect of training that is also embedded in the Using PROMs to Improve Service Effectiveness for Supervisors (UPROMISES) training.

\section{Aims of the present research}

The above evidence suggests that training clinicians to use outcome measures may be associated with increased positive attitudes and self-efficacy related to using PROMs (e.g., (Edbrooke-Childs, Wolpert, et al., 2016). Still, evidence is needed to examine whether 
training has an impact on changes to work practices and the possible mechanisms of change. Moreover, evidence on the effect of training has involved self-reported attitudes and selfefficacy, meaning that evidence demonstrating changes to practice from other reporters is also required. Therefore, the aim of the present research was to examine the impact of training in the use of PROMs on clinical practice using a mixed-methods, observational design. Given the importance of leadership and management support when implementing changes to practice, the present research focuses on training delivered to supervisors on the use of PROMs in clinical supervision.

\section{Methods}

\section{Overview of UPROMISES training}

As we have described elsewhere (Edbrooke-Childs, Wolpert, et al., 2016), UPROMISES was developed by the Child Outcomes Research Consortium (CORC) (Fleming, Jones, Bradley, \& Wolpert, 2016) and the Evidence Based Practice Unit (M. Wolpert et al., 2012) with additional input from Common Room (a young-person advocacy organisation) and clinicians linked to the CYP IAPT service improvement programme. The curriculum, structure and learning activities of the training were based on previous projects in child mental health services across England: a three-year Masterclass series for promoting evidence-based, outcomes-informed practice and user participation (Childs, 2013) and a project to develop and promote shared decision making (Abrines-Jaume et al., 2016). In addition to expert input from child mental health professionals and service users, literature on training development and evaluation for adult learners and professional audiences was used in the development, design, delivery and evaluation of UPROMISES (Booth, Sutton, \& Falzon, 2003; Law, 2012; Michelson et al., 2011; The Health Foundation, 2012). The version of UPROMISES used in the present research focused on three-day training for supervisors in the use of PROMS in clinical supervision. The three core topics covered in UPROMISES are 
supervision clinicians on: 1) choosing appropriate PROMs to use with patients, 2) interpreting the meaning of feedback from PROMs, and 3) identifying and making any changes to therapy based on feedback from PROMs.

A pre-post observational design was employed to evaluate the UPROMISES training, comprising two components. First, supervisors completed measures up to four weeks before training (Time 1, T1) and at the very end of training (Time 2, T2). Second, supervisors were asked to nominate a supervisee to be interviewed about how supervision had changed after UPROMISES, and telephone interviews were arranged according to supervisees' availability; six supervisees (all female, no supervisee had the same supervisor) agreed to take part in an interview, forming the participants for the qualitative data. Supervisors were required to video-record supervision sessions after the three-day training, which were used for accreditation and to triangulate the questionnaire and interview data. Overall, nine videos were observed and rated by course trainers.

\section{Participants and procedure}

Of 75 UPROMISES attendees, 55\% completed both T1 and T2 questionnaires, resulting in a final sample of $N=41$ supervisors (31 female, 10 male). Supervisors were psychologists $(22 \%)$, family therapists $(12 \%)$, counsellors $(10 \%)$, child and adolescent psychotherapists, other unqualified staff ( $7 \%$ each), occupational therapists, medics, nurses, primary mental health workers (5\% each), creative therapists, educational professionals, and other qualified staff ( $2 \%$ each), with $16 \%$ unspecified. The majority had direct patient contact (2\% unspecified) varying from 1-5 hours per week (10\%), 6-10 hours (17\%), 11-15 hours (24\%), 16-20 hours $(24 \%)$, to 21 or more hours (15\%). Attendees supervised 0 colleagues (22\%), 1-5 colleagues (54\%), 6-10 colleagues (12\%), 11-15 colleagues $(7 \%)$, or $16-20$ colleagues (5\%). In supervision with these colleagues, participants reported using PROMs 
with no supervisees $(44 \%)$, with a few supervisees $(20 \%)$, with most supervisees $(29 \%)$, or with all supervisees $(5 \%)$ ( $2 \%$ unspecified).

\section{Measures}

\section{PROM attitudes and feedback attitudes}

To measure PROM attitudes and feedback attitudes, the 23-item Routine Outcome Assessment (ROA) was used (Willis, Deane, \& Coombs, 2009). The ROA measures general attitudes to administering and using outcome measures (15 items; e.g., "Outcome measures do not capture what is happening for my patients") and attitudes to using and providing feedback based on outcome measures ( 8 items; e.g., "Providing feedback from outcome measures will help the clinician and service user work more collaboratively in treatment"). Responses were given on a six-point scale from strongly disagree (1) to strongly agree (6). The ROA has been used in previous studies and demonstrated reliability (Edbrooke-Childs, Wolpert, et al., 2016; Willis, et al., 2009). Table 1 shows the Cronbach's alphas, which were acceptable.

\section{Routine outcome self-efficacy in supervision}

To measure PROM self-efficacy, a bespoke Routine Outcome Self-Efficacy in Supervision (ROSES) questionnaire was used as we were unable to find an existing measure. The structure of ROSES was based on an existing measure of self-efficacy regarding mental health diagnosis (Michelson, et al., 2011). Attendees were asked the initial question stem "How well do you feel able to perform the following activities?". Next, a list of activities was presented related to PROM self-efficacy for child mental health service staff supervising colleagues (9 items; e.g., "Supervise others in determining collaboratively with service users the main areas to work on and record and monitor each session") (Children and Young People's Improving Access to Psychological Therapies Programme, 2013). Supervisors 
responded on a six-point scale from not at all well (1) to extremely well (6). Table 1 shows the Cronbach's alphas, which were acceptable.

\section{Interview schedules}

Semi-structured interview schedules were developed based on items from the ROA and ROSES questionnaires and explored supervisees' experience and perceptions of changes in supervision (e.g., "have you noticed any changes in supervision since your supervisor attended UPROMISE training?"), in the service (e.g. "have you noticed any changes in the service more broadly?"), in aspects of their supervisor's work (e.g. "Has your supervisor's ability to collaboratively use PROMs and outcome data in supervision changed since attending UPROMISE training?’), and 12-items exploring changes in the frequency of performance of specific tasks in supervision (e.g., "regularly monitors my use of measures", "thinks about how to offer feedback to service users").

\section{Observation tool}

A non-participant observation tool was developed based on items from the ROA and ROSES questionnaires and explored supervisors' behaviours in supervision. In particular, 7 items included the initial question stem: "How well did the supervisor perform the following activities?" Next, a list of activities was presented related to PROM efficacy for child mental health service staff supervising colleagues (e.g., "Demonstrate an appropriate understanding of the use of PROMs/feedback tools in clinical practice") (Children and Young People's Improving Access to Psychological Therapies Programme, 2013). Three observers responded on a four-point scale from not at all well (1) to extremely well (4) with two additional options not used in scoring (i.e., not performed, not applicable). Observers were trained in using the observation tools as part of training in delivering the UPROMISES course.

\section{Analytic strategy}


To explore change in attitudes and self-efficacy associated with training, as recorded in the pre-post self-report questionnaires, paired samples t-tests were conducted and standardised effect sizes were calculated by dividing the pre-post difference in means by the standard deviation at $\mathrm{T} 1$.

\section{Results}

\section{Change associated with training}

The results of the paired samples t-tests conducted on the 41 included supervisors are shown in Table 1. PROM attitudes, feedback attitudes, and self-efficacy all significantly increased from T1 to T2 with moderate to large effect sizes (Cohen, 1988). Supervisors had more positive attitudes to administering PROMs and using feedback from PROMs, and had higher levels of self-efficacy about using PROMs in supervision, after training.

[INSERT TABLE 1 HERE]

\section{Supervisee interviews}

The nine supervisee interviews were transcribed verbatim and a thematic analysis was conducted using Atlas.ti. Two core themes emerged from the interviews.

\section{Increased positive attitudes and self-efficacy related to using PROMs and use of}

PROMs in supervision. Supervisees noted changes in supervision regarding their

supervisor's use of PROMs or their own individual use of PROMs. In line with the increases in positive attitudes toward PROMs and feedback from the quantitative data, supervisees commented that supervisors used PROMs to a greater extent after training: "I think we've been trying where possible to think about outcome measures more", "it's more frequently on our agenda and we're thinking together about what other measures we might want to add or use". Dovetailing with the increases in self-efficacy, supervisees commented that supervisors were more confident in their use of PROMs in supervision: "He's more confident when I raise something", "I've noticed the difference is how kind of confident she is using them", 
"He would be more able to respond if I ask something specific", "He's more familiar with the outcome measures and with how to use them". In contrast, some supervisees felt that little had changed in supervision since UPROMISES, commenting that either no change was needed (i.e., that their supervisor already routinely used PROMs in supervision) or that training alone was insufficient to change practice and further interventions would be required (see below).

\section{Contextual challenges to implementing changes to practice are an ongoing barrier.}

Aligning with the second theme, some supervisees noted that training alone was insufficient to change practice, mainly due to other contextual changes - "A major [child and adolescent mental health services] transformation" concurrently occurring in their service. Supervisees described the use of PROMs in supervision as being "overshadowed by other things that have been happening in the organisation; there's been a lot of changes in our organisation". These wider contextual changes were described as "a bit beyond [the supervisor's] control...because of our team situation" and "So those things have all interrupted [the use of PROMs in supervision]".

\section{Observation tool}

Observer ratings for each supervisor are shown in Table 2. Of the supervisors for whom an observation tool was completed, supervisors' total scores were: one supervisor received $16 / 28(57 \%)$, one $18 / 28(64 \%)$, two $21 / 28(75 \%)$, one $23 / 28(82 \%)$, and four $24 / 28(86 \%)$.

Items 1,2 , and 4 had the greatest range of ratings, and these items all refer to the discussion of the administration of PROMs in supervision. This may suggest that although supervisors had more positive attitudes and higher levels of self-efficacy related to administering PROMs after training, supervisors were not entirely consistent in discussing, in supervision with clinicians, how PROMs were administered in clinical sessions. Three videos were rated by 
two observers who gave the same ratings except for two items where there was a one-point difference.

[INSERT TABLE 2 HERE]

\section{Discussion}

The aim of the present research was to examine the impact of training in the use of PROMs on clinical practice using a mixed-methods, observational design. Given the importance of leadership and management support when implementing changes to practice, the present research focuses on training delivered to supervisors in the use of PROMs in clinical supervision, exploring the idea that supervision action may influence implementation through teams, promoting consistent organisational, attitudinal, and behavioural change.

Triangulating the results of the pre-post self-report questionnaires and interviews with supervisees suggests that UPROMISES training was associated with an increase in supervisors' positive attitudes and self-efficacy related to using PROMs and use of PROMs in supervision. In addition, the completed observations tools dovetailed with these findings and indicated that supervisors had high levels of competence related to discussing PROMs in supervision. Still, supervisors were not entirely consistent in discussing in supervision with clinicians how PROMs were administered.

The finding that supervisors' positive attitudes and self-efficacy related to PROMs increased after training is in line with previous evidence on training clinicians in the use of PROMs in clinical practice (Edbrooke-Childs, Wolpert, et al., 2016). Moreover, they are also in line with previous findings demonstrating the association between negative attitudes and low levels of knowledge, self-efficacy and use of PROMs (Aoun, et al., 2002; Burgess, et al., 2012; Crocker \& Rissel, 1998). The finding that some supervisees reported a lack of change in supervision after UPROMISES because supervisors were already routinely using PROMs in supervision, or because of competing service changes, is in line with implementation 
science literature that there are number of moderators of the impact of training on changes to practice (Elliott, et al., 2003; Mellor-Clark, et al., 2016; The Health Foundation, 2012). In a context where concurrent, competing organisation transformations are often underway, findings of the present research suggest that it is crucial for any service change intervention to equip trainees with the skills to embed new practices despite competing demands for time and resources. Such competing priorities may partially explain the finding from the nonparticipant observations that supervisors' discussions with clinicians in supervision about the administration of PROMs in clinical sessions were inconsistent.

Limitations should be considered when interpreting the findings of the present research. An observational design was employed, and inferences of causation should not be made as random allocation and a control condition were not used. Similarly, there may have been a self-selection bias in terms of both those who attended UPROMISES and those took part in the study. In particular, although a range of views were expressed in the interviews, supervisees may have been reticent to give negative reports of their supervisor, despite the anonymity and confidentiality of the research being communicated. A small sample was included and there was some attrition between supervisors who completed the T1 and T2 questionnaires, potentially limiting the generalisability of the findings to other supervisors in child and adolescent mental health services.

\section{Conclusion}

Notwithstanding the above limitations, the findings of the present research suggest that UPROMISES training was associated with an increase in supervisors' positive attitude and self-efficacy related to using PROMs and their use of PROMs in supervision. Moreover, findings were triangulated between self-reported questionnaires, interviews with supervisees, and non-participant observations of video-recorded supervision sessions. The findings of the present research are in line with the growing body of evidence that training child mental 
health staff to use PROMs may be associated with changes in attitudes, self-efficacy and use of PROMs (Edbrooke-Childs, et al., submitted; Edbrooke-Childs, Wolpert, et al., 2016).

Future research should examine the role of other forms of leadership and management support in the implementation and sustained use of PROMs. 
Table 1.

Descriptive statistics for PROM and feedback attitudes and PROM self-efficacy.

\begin{tabular}{lccccc}
\hline & $M$ & $S D$ & $t$ & $d$ & $\alpha$ \\
\hline ROA & & & & & \\
T1 PROM attitudes & 4.48 & 0.39 & & & .70 \\
T2 PROM attitudes & 4.74 & 0.45 & & & .80 \\
T1 feedback attitudes & 4.80 & 0.50 & & & .75 \\
T2 feedback attitudes & 4.97 & 0.51 & & & .82 \\
ROSES & & & & & \\
T1 PROM self-efficacy & 2.83 & 1.09 & & & .964 \\
T2 PROM self-efficacy & 3.91 & 1.07 & & & .94 \\
\hline
\end{tabular}

Note. $N=41$. ROA = Routine Outcome Assessment questionnaire (Willis et al., 2009). ROSES $=$ Routine Outcome Self-Efficacy in Supervision questionnaire. PROM = Patient Reported Outcome Measure. 
Table 2.

Ratings for the non-participant observation tool.

\begin{tabular}{|c|c|c|c|c|c|c|c|c|c|}
\hline & \multicolumn{9}{|c|}{ Participant } \\
\hline & 1 & 2 & 3 & 4 & 5 & 6 & 7 & 8 & 9 \\
\hline $\begin{array}{l}\text { Demonstrate an appropriate } \\
\text { understanding of the use of } \\
\text { PROMS/feedback tools in } \\
\text { clinical practice }\end{array}$ & 4 & 4 & 4 & 4 & 4 & 2 & 3 & 3 & 3 \\
\hline $\begin{array}{l}\text { Reflect on the appropriate } \\
\text { use of the PROMs/feedback } \\
\text { tools }\end{array}$ & 4 & 4 & 4 & 4 & 4 & 2 & 3 & 3 & 4 \\
\hline $\begin{array}{l}\text { Demonstrate understanding, } \\
\text { and appropriate use, of } \\
\text { information from the } \\
\text { PROMs/feedback tools and } \\
\text { their limitations }\end{array}$ & 4 & 4 & 4 & 4 & 4 & 3 & 4 & 3 & 4 \\
\hline $\begin{array}{l}\text { Advise the supervisee on the } \\
\text { use of the PROMs/feedback } \\
\text { tools } \\
\text { Integrate the use of } \\
\text { information from }\end{array}$ & 4 & 4 & 4 & 4 & 4 & 2 & $\mathrm{n} / \mathrm{a}$ & 3 & 4 \\
\hline $\begin{array}{l}\text { PROMs/feedback tools into } \\
\text { supervision, drawing on } \\
\text { other clinical information }\end{array}$ & 3 & 4 & 4 & 4 & 4 & 3 & 3 & 3 & 4 \\
\hline $\begin{array}{l}\text { Supervise in a facilitative } \\
\text { and collaborative manner }\end{array}$ & 4 & 4 & 4 & 4 & 4 & 3 & 4 & 3 & 4 \\
\hline $\begin{array}{l}\text { Encourage the supervisee to } \\
\text { critically reflect on, or show } \\
\text { appropriate } \\
\text { understanding of the use of, } \\
\text { the feedback and outcomes } \\
\text { tools from the } \\
\text { perspective of the young } \\
\text { person or family }\end{array}$ & 4 & 4 & 4 & 4 & 4 & 3 & 4 & 3 & 3 \\
\hline
\end{tabular}

Note. $N=9$. The initial question stem "How well did the supervisor perform the following activities?" was used. Observers responded on a four-point scale from not at all well (1) to extremely well (4). 


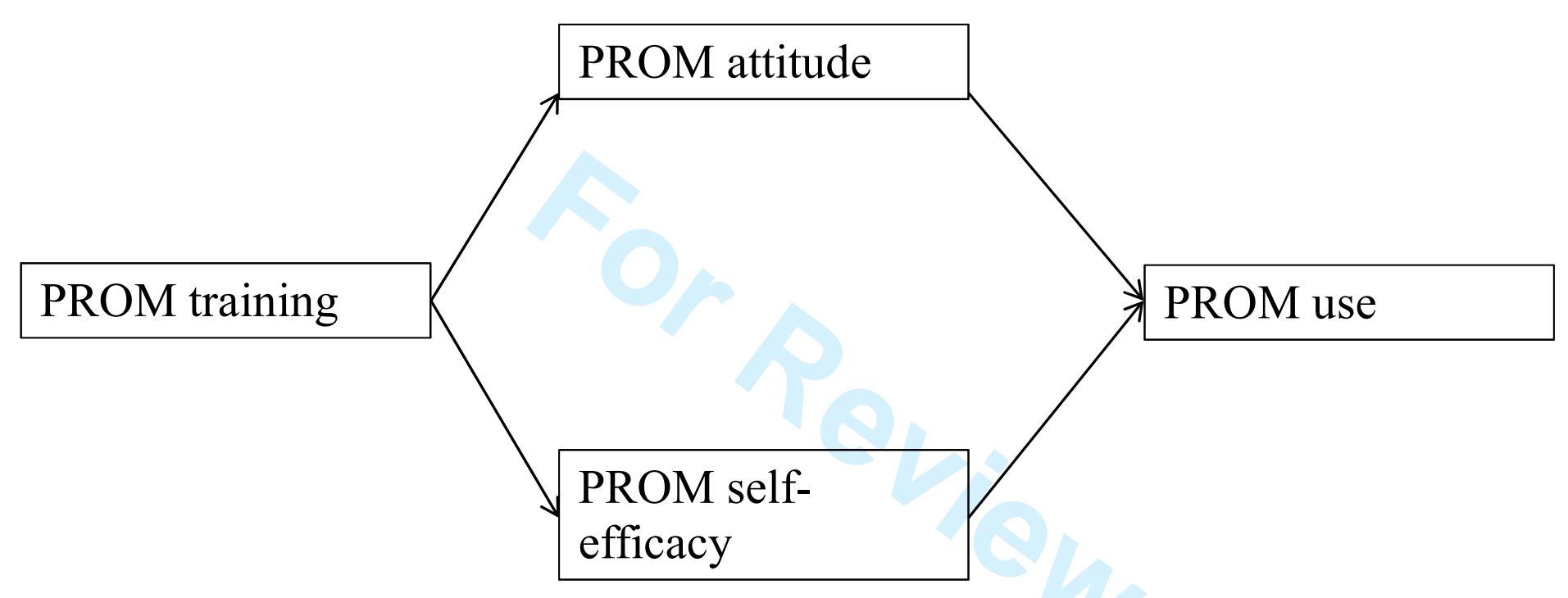

Figure 1

Theoretical relationships between PROM training, attitude, self-efficacy, and use.

Note. $\mathrm{PROM}=$ patient-reported outcome measure. 


\section{Acknowledgements}

Study funding: This study was funded by NHS England.

Conflicts of interest: Law, Martin, and Wolpert were involved in the design and delivery of the UPROMISES training

Contributorships: All authors contributed to the conception and design, or collection, analysis and interpretation of data; and drafting the article or revising it critically for important intellectual content and final approval of the version to be published.

Ethical approval: All procedures performed in studies involving human participants were in accordance with the ethical standards of the institutional and/or national research committee and with the 1964 Helsinki declaration and its later amendments or comparable ethical standards. 


\section{References}

Abrines-Jaume, N., Midgley, N., Hopkins, K., Hoffman, J., Martin, K., Law, D., \& Wolpert, M. (2016). A qualitative analysis of implementing shared decision making in Child and Adolescent Mental Health Services in the United Kingdom: Stages and facilitators. Clinical Child Psychology and Psychiatry, 21(1), 19-31. doi: 10.1177/1359104514547596

Aoun, S., Pennebaker, D., \& Janca, A. (2002). Outcome measurement in rural mental health care: a field trial of rooming-in models. Australian Journal of Rural Health, 10(6), 302-307. doi: 10.1046/j.1440-1584.2002.00484.x

Batalden, P., \& Davidoff, F. (2007). Teaching quality improvement: The devil is in the details. JAMA, 298(9), 1059-1061. doi: 10.1001/jama.298.9.1059

Batty, M. J., Moldavsky, M., Foroushani, P. S., Pass, S., Marriott, M., Sayal, K., \& Hollis, C. (2013). Implementing routine outcome measures in child and adolescent mental health services: from present to future practice. Child and Adolescent Mental Health, 18(2), 82-87. doi: 10.1111/j.1475-3588.2012.00658.x

Bearman, S. K., Schneiderman, R. L., \& Zoloth, E. (2016). Building an Evidence Base for Effective Supervision Practices: An Analogue Experiment of Supervision to Increase EBT Fidelity. [journal article]. Administration and Policy in Mental Health and Mental Health Services Research, 1-15. doi: 10.1007/s10488-016-0723-8

Bickman, L., Kelley, S. D., Breda, C., de Andrade, A. R., \& Riemer, M. (2011). Effects of routine feedback to clinicians on mental health outcomes of youths: results of a randomized trial. Psychiatric Services, 62(12), 1423-1429. doi: 10.1176/appi.ps.002052011

Booth, A., Sutton, A., \& Falzon, L. (2003). Working together: supporting projects through action learning. Health Information \& Libraries Journal, 20(4), 225-231. doi: 10.1111/j.1471-1842.2003.00461.x

Boswell, J. F., Kraus, D. R., Miller, S. D., \& Lambert, M. J. (2013). Implementing routine outcome monitoring in clinical practice: Benefits, challenges, and solutions. Psychotherapy Research, 25(1), 6-19. doi: 10.1080/10503307.2013.817696

Bradshaw, T., Butterworth, A., \& Mairs, H. (2007). Does structured clinical supervision during psychosocial intervention education enhance outcome for mental health nurses and the service users they work with? Journal of Psychiatric and Mental Health Nursing, 14(1), 4-12. doi: 10.1111/j.1365-2850.2007.01021.x

Burgess, P., Coombs, T., Clarke, A., Dickson, R., \& Pirkis, J. (2012). Achievements in mental health outcome measurement in Australia: Reflections on progress made by the Australian Mental Health Outcomes and Classification Network (AMHOCN). [journal article]. International Journal of Mental Health Systems, 6(1), 1-11. doi: 10.1186/1752-4458-6-4

Carlier, I. V. E., Meuldijk, D., Van Vliet, I. M., Van Fenema, E., Van der Wee, N. J. A., \& Zitman, F. G. (2012). Routine outcome monitoring and feedback on physical or mental health status: evidence and theory. Journal of Evaluation in Clinical Practice, 18(1), 104-110. doi: 10.1111/j.1365-2753.2010.01543.x

Children and Young People's Improving Access to Psychological Therapies Programme. (2013). National curriculum for core, cognitive behavioural therapy, parenting training (3-10 year olds), systemic family practice, interpersonal psychotherapy for adolescents, supervision, and transformational service leadership. London: IAPT.

Childs, J. (2013). Evaluation Report: Masterclasses: Promoting excellence in evidence-based outcomes informed practice \& user participation for child mental health professionals. London: CAMHS EBPU. 
Cohen, J. (1988). Statistical Power Analysis for the Behavioral Sciences. (2nd ed.). New York: Erlbaum.

Crocker, T., \& Rissel, C. (1998). Knowledge of and attitudes to the health outcomes approach among community mental health professionals. Australian Health Review, 21(4), 111126.

de Jong, K., van Sluis, P., Nugter, M. A., Heiser, W. J., \& Spinhoven, P. (2012).

Understanding the differential impact of outcome monitoring: Therapist variables that moderate feedback effects in a randomized clinical trial. Psychotherapy Research, 22(4), 464-474. doi: 10.1080/10503307.2012.673023

Department of Health. (2011). Talking therapies: A four-year plan of action. London: Department of Health.

Douglas, S., Button, S., \& Casey, S. E. (2014). Implementing for sustainability: Promoting use of a Measurement Feedback System for innovation and quality improvement. Administration and Policy in Mental Health and Mental Health Services Research. doi: 10.1007/s10488-014-0607-8

Edbrooke-Childs, J., Barry, D., Rodriguez, I. R., Papageorgiou, D., Wolpert, M., \& Schulz, J. (submitted). Patient reported outcome measures in child and adolescent mental health services: Associations between clinician demographic characteristics, attitudes, and efficacy.

Edbrooke-Childs, J., Gondek, D., Deighton, J., Fonagy, P., \& Wolpert, M. (2016). When is sessional monitoring more likely in child and adolescent mental health services? Administration and Policy in Mental Health and Mental Health Services Research, 43(3), 316-324. doi: 10.1007/s10488-016-0725-6

Edbrooke-Childs, J., Wolpert, M., \& Deighton, J. (2016). Using Patient Reported Outcome Measures to Improve Service Effectiveness (UPROMISE): Training clinicians to use outcome measures in child mental health. Administration and Policy in Mental Health and Mental Health Services Research, 43(3), 302-308. doi: 10.1007/s10488-0140600-2

Elliott, S. A., Ashton, C., Gerrard, J., \& Cox, J. L. (2003). Is trainer training an effective method for disseminating evidence-based practice for postnatal depression? Journal of Reproductive and Infant Psychology, 21(3), 219-228. doi: 10.1080/0264683031000154980

Fixsen, D. L., Naoom, S. F., Blase, K. A., Friedman, R. M., \& Wallace, F. (2005). Implementation research: A synthesis of the literature. Tampa, Fl: University of South Florida, Louise de la Parte Florida Mental Health Institute, The National Implementation Research Netowrk.

Fleming, I., Jones, M., Bradley, J., \& Wolpert, M. (2016). Learning from a learning collaboration: the CORC approach to combining research, evaluation and practice in child mental health. Administration and Policy in Mental Health and Mental Health Services Research, 43(3), 297-301. doi: 10.1007/s10488-014-0592-y

Gondek, D., Edbrooke-Childs, J., Fink, E., Deighton, J., \& Wolpert, M. (2016). Feedback from Outcome Measures and Treatment Effectiveness, Treatment Efficiency, and Collaborative Practice: A Systematic Review. Administration and Policy in Mental Health and Mental Health Services Research, 43(3), 325-343. doi: 10.1007/s10488015-0710-5

Hall, C. L., Moldavsky, M., Baldwin, L., Marriott, M., Newell, K., Taylor, J., . . Hollis, C. (2013). The use of routine outcome measures in two child and adolescent mental health services: a completed audit cycle. BMC Psychiatry, 13(1), 270. doi: 10.1186/1471-244X-13-270 
Herschell, A. D., Kolko, D. J., Baumann, B. L., \& Davis, A. C. (2010). The Role of Therapist Training in the Implementation of Psychosocial Treatments: A Review and Critique with Recommendations. Clinical Psychology Review, 30(4), 448-466. doi: 10.1016/j.cpr.2010.02.005

Hoag, B. G., Ritschard, H. V., \& Cooper, C. L. (2002). Obstacles to effective organizational change: the underlying reasons. Leadership \& Organization Development Journal, 23(1), 6-15. doi: 10.1108/01437730210414526

Jensen-Doss, A., \& Hawley, K. M. (2010). Understanding Barriers to Evidence-Based Assessment: Clinician Attitudes Toward Standardized Assessment Tools. Journal of Clinical Child \& Adolescent Psychology, 39(6), 885-896. doi: 10.1080/15374416.2010.517169

Johnston, C., \& Gowers, S. (2005). Routine Outcome Measurement: A Survey of UK Child and Adolescent Mental Health Services. Child and Adolescent Mental Health, 10(3), 133-139. doi: 10.1111/j.1475-3588.2005.00357.x

Kihlgren, M., \& Hansebo, G. (2014). Organizational Change and Supervision. In C. E. Watkins Jr \& D. L. Milne (Eds.), The Wiley International Handbook of Clinical Supervision. Oxford, UK: John Wiley \& Sons.

Kolb, D. A. (1984). Experiential learning: experience as the source of learning and development. Englewood Cliffs, NJ: Prentice Hall.

Lambert, M. J., Whipple, J. L., Hawkins, E. J., Vermeersch, D. A., Nielsen, S. L., \& Smart, D. W. (2003). Is It Time for Clinicians to Routinely Track Patient Outcome? A MetaAnalysis. Clinical Psychology: Science and Practice, 10(3), 288-301. doi: 10.1093/clipsy.bpg025

Law, D. (2012). A Practical Guide to Using Service User Feedback \& Outcome Tools to Inform Clinical Practice in Child \& Adolescent Mental Health Some initial guidance from the Children and Young Peoples' Improving Access to Psychological Therapies Outcomes-Oriented Practice (CO-OP) Group Retrieved from http://www.iapt.nhs.uk/silo/files/a-practical-guide-to-using-service-user-feedback-outcome-tools-.pdf

Lucock, M., Halstead, J., Leach, C., Barkham, M., Tucker, S., Randal, C., . . Saxon, D. (2015). A mixed-method investigation of patient monitoring and enhanced feedback in routine practice: Barriers and facilitators. Psychotherapy Research, 25(6), 633-646. doi: 10.1080/10503307.2015.1051163

Mellor-Clark, J., Barkham, M., Connell, J., \& Evans, C. (1999). Practice-based evidence and standardized evaluation: Informing the design of the CORE system. European Journal of Psychotherapy \& Counselling, 2(3), 357-374. doi: 10.1080/13642539908400818

Mellor-Clark, J., Cross, S., Macdonald, J., \& Skjulsvik, T. (2016). Leading horses to water: Lessons from a decade of helping psychological therapy service use routine outcome measurement to improve practice. Administration and Policy in Mental Health and Mental Health Services Research, 43(3), 279-285. doi: 10.1007/s10488-014-0587-8

Michelson, D., Rock, S., Holliday, S., Murphy, E., Myers, G., Tilki, S., \& Day, C. (2011). Improving psychiatric diagnosis in multidisciplinary child and adolescent mental health services. [10.1192/pb.bp.111.034066]. The Psychiatrist, 35(12), 454-459.

Milne, D. L. (2016). Guiding CBT supervision: how well do manuals and guidelines fulfil their promise? the Cognitive Behaviour Therapist, 9, e1. doi: 10.1017/S1754470X15000720

Moran, P., Kelesidi, K., Guglani, S., Davidson, S., \& Ford, T. (2012). What do parents and carers think about routine outcome measures and their use? A focus group study of 
CAMHS attenders. Clinical Child Psychology and Psychiatry, 17(1), 65-79. doi: $10.1177 / 1359104510391859$

O'Donovan, A., Halford, W. K., \& Walters, B. (2011). Towards Best Practice Supervision of Clinical Psychology Trainees. Australian Psychologist, 46(2), 101-112. doi: 10.1111/j.1742-9544.2011.00033.x

Oordt, M. S., Jobes, D. A., Fonseca, V. P., \& Schmidt, S. M. (2009). Training Mental Health Professionals to Assess and Manage Suicidal Behavior: Can Provider Confidence and Practice Behaviors be Altered? Suicide and Life-Threatening Behavior, 39(1), 21-32. doi: 10.1521/suli.2009.39.1.21

Roth, A., \& Pilling, S. (2008). A competence framework for the supervision of psychological therapies Retrieved April 18, 2016

Rousmaniere, T. G., Swift, J. K., Babins-Wagner, R., Whipple, J. L., \& Berzins, S. (2016). Supervisor variance in psychotherapy outcome in routine practice. Psychotherapy Research, 26(2), 196-205. doi: 10.1080/10503307.2014.963730

SAMHSA's National Registry of Evidence-Based Programs and Practices. (2015). Partners for Change Outcome Management System (PCOMS): International Centre for Clinical Excellence Retrieved June 2015, from http://www.nrepp.samhsa.gov/ViewIntervention.aspx?id=249

Schoenwald, S. K., Sheidow, A. J., \& Chapman, J. E. (2009). Clinical supervision in treatment transport: Effects on adherence and outcomes. Journal of Consulting and Clinical Psychology, 77(3), 410-421. doi: 10.1037/a0013788

The Health Foundation. (2012). Quality improvement training for healthcare professionals. London: The Health Foundation.

Trauer, T., Pedwell, G., \& Lisa, G. (2009). The effect of guidance in the use of routine outcome measures in clinical meetings. Australian Health Review(33), 144-151. doi: 10.1071/AH090144

Turpin, G., \& Wheeler, S. (2011). IAPT Supervision Guidance: University of Sheffield, University of Leicester.

Walter, G., Cleary, M., \& Rey, J. (1998). Attitudes of mental health personnel towards rating outcome. Journal of Quality in Clinical Practice, 18(2), 109-115.

Watkins, C. E. (2011). Does Psychotherapy Supervision Contribute to Patient Outcomes? Considering Thirty Years of Research. The Clinical Supervisor, 30(2), 235-256. doi: 10.1080/07325223.2011.619417

Watkins Jr, C. E., \& Milne, D. L. (Eds.). (2014). The Wiley International Handbook of Clinical Supervision. Oxford, UK: John Wiley \& Sons.

White, E., \& Winstanley, J. (2010). A randomised controlled trial of clinical supervision: selected findings from a novel Australian attempt to establish the evidence base for causal relationships with quality of care and patient outcomes, as an informed contribution to mental health nursing practice development. Journal of Research in Nursing, 15(2), 151-167. doi: 10.1177/1744987109357816

Willis, A., Deane, F. P., \& Coombs, T. (2009). Improving clinicians' attitudes toward providing feedback on routine outcome assessments. International Journal of Mental Health Nursing, 18(3), 211-215. doi: 10.1111/j.1447-0349.2009.00596.x

Wolpert, M., Curtis-Tyler, K., \& Edbrooke-Childs, J. (2016). A qualitative exploration of patient and clinician views on Patient Reported Outcome Measures in child mental health and diabetes services. Administration and Policy in Mental Health and Mental Health Services Research, 43(3), 309-315. doi: 10.1007/s10488-014-0586-9

Wolpert, M., Ford, T., Trustam, E., Law, D., Deighton, J., Flannery, H., \& Fugard, A. (2012). Patient-reported outcomes in child and adolescent mental health services (CAMHS): 
TRAINING SUPERVISORS TO USE PROMS 6

use of idiographic and standardized measures. Journal of Mental Health, 21(2), $165-$ 173. doi: 10.3109/09638237.2012.664304 